\title{
The association between adiponectin, HDL-cholesterol and $\alpha 1$-antitrypsin-LDL in female subjects without metabolic syndrome
}

\author{
Kazuhiko Kotani*, Toshiyuki Yamada, Nobuyuki Taniguchi
}

\begin{abstract}
Background: Oxidized low-density lipoprotein (LDL) may act as an atheroprotective (anti-atherosclerotic) agent under some conditions. While the $\alpha 1$-antitrypsin (AT)-LDL complex is considered a type of oxidized LDL, its clinical relevance remains unknown. The aim of the present study was to investigate the association between AT-LDL and anti-atherosclerotic variables such as HDL-cholesterol and adiponectin in subjects with and without metabolic syndrome (MetS).

Methods: In asymptomatic females ( $n=194$; mean age, 54 years) who were divided into non-MetS $(n=108)$ and MetS groups ( $n=86$ ), the fasting levels of serum AT-LDL, adiponectin and glucose/lipid panels were measured, in addition to body mass index (BMI) and blood pressure.

Results: The MetS group showed significantly higher BMI, blood pressure, glucose and triglyceride levels as well as significantly lower levels of HDL-cholesterol and adiponectin than the non-MetS group. A multivariate-adjusted analysis revealed that in the non-MetS group, AT-LDL was significantly, independently and positively correlated with adiponectin $(\beta=0.297, \mathrm{P}<0.05)$, along with HDL-cholesterol $(\beta=0.217, \mathrm{P}<0.05)$. In the MetS group, AT-LDL was significantly, independently and positively correlated with LDL-cholesterol only $(\beta=0.342, P<0.05)$.

Conclusions: These data suggest that AT-LDL may exert anti-atherosclerotic effects in female subjects without MetS. More studies are required to clarify the clinical roles of AT-LDL in relation to the pathophysiology of MetS.
\end{abstract}

\section{Background}

Atherosclerosis is an important health concern, because it leads to cardiovascular disease [1]. Oxidation of low-density lipoprotein (LDL) is involved in the atherosclerotic processes, and oxidized LDL (oxLDL) can exhibit atherogenic properties [2,3]. Recent research has shown that various types of oxLDL exist both in atherosclerotic lesions and in the circulation, and the circulating oxLDL is presently thought to be a useful marker reflecting one's atherosclerotic state [4-6]. On the other hand, it is becoming increasingly clear that oxLDL exerts dual effects on atherosclerosis [7-15]. Namely, low levels (small amounts) of oxLDL can exert an atheroprotective (anti-atherosclerotic) effect. However, the

\footnotetext{
* Correspondence: kazukotani@jichi.ac.jp

Department of Clinical Laboratory Medicine, Jichi Medical University, Tochigi,
} Japan

\section{Biomed Central}

(c) 2010 Kotani et al; licensee BioMed Central Ltd. This is an Open Access article distributed under the terms of the Creative Commons Attribution License (http://creativecommons.org/licenses/by/2.0), which permits unrestricted use, distribution, and reproduction in any medium, provided the original work is properly cited. clinical data about this phenomenon are limited, and more clinical investigations are needed.

While $\alpha 1$-antitrypsin (AT), a serine-proteinase inhibitor, protects tissues from damage caused by excess activities of proteinases [16], when AT is oxidized, it loses its inhibitory activity and activates monocytes [17]. Oxidized AT has been shown to form a complex with LDL in atherosclerotic lesions, and the circulating AT-LDL complex seems to reflect the atherosclerotic state, although the precise mechanisms underlying the formation of the AT-LDL complex remain undetermined [18]. Importantly, the clinical significance of AT-LDL, as an oxLDL marker, in atherosclerosis is unknown. In our previous study of a specific atherosclerosis-prone population with obesity and metabolic syndrome (MetS), we did not find any significant role for AT-LDL [19]. However, in agreement with the original report that developed the AT-LDL measurement 
system [18], we have also noted that the circulating levels of AT-LDL were very low in these patients [19].

This prompted us to investigate the association between circulating AT-LDL and anti-atherosclerotic variables, such as high-density lipoprotein (HDL) and adiponectin [20]. The levels of these variables generally differ between subjects with and without MetS (in particular, adiponectin has recently attracted much attention because of its association with MetS) [20]. The clinical relationship between AT-LDL and these variables should be examined with regard to a potential role in MetS. Therefore, the aim of the present study was to determine whether there was a correlation between AT-LDL and atherosclerotic variables, including HDL-cholesterol and adiponectin, in subjects with and without MetS.

\section{Subjects and Methods}

A total of 194 non-medicated and asymptomatic female participants, ranging from 35-70 years of age, were recruited during routine check-ups in the health education classes and outpatient clinics. The study population was composed of subjects without MetS $(\mathrm{n}=108)$ and with MetS $(n=86)$ (Table 1). The eligible subjects had no histories of cardiovascular, thyroid, hematological, kidney or liver diseases. The existence of 3 out of 5 of the following criteria constituted a diagnosis of MetS according to the National Cholesterol Education Program Adult Treatment Panel (NCEP-ATP) III recommendations [21]: 1) obesity identified by a body mass

\begin{tabular}{|c|c|c|c|}
\hline Variable & $\begin{array}{l}\text { Non-MetS } \\
(n=108)\end{array}$ & $\begin{array}{c}\text { MetS } \\
(n=86)\end{array}$ & $P$ value \\
\hline Age, years & $54.1 \pm 9.6$ & $53.4 \pm 9.5$ & 0.618 \\
\hline Current smoking, \% & 9.3 & 10.5 & 0.779 \\
\hline Body mass index, $\mathrm{kg} / \mathrm{m}^{2}$ & $26.0 \pm 2.5$ & $27.5 \pm 1.7$ & $<0.0001^{* *}$ \\
\hline $\begin{array}{l}\text { Systolic blood pressure, } \\
\mathrm{mmHg}\end{array}$ & $130 \pm 17$ & $146 \pm 17$ & $<0.0001^{* *}$ \\
\hline $\begin{array}{l}\text { Diastolic blood pressure, } \\
\mathrm{mmHg}\end{array}$ & $79 \pm 11$ & $87 \pm 10$ & $<0.0001^{* *}$ \\
\hline $\begin{array}{l}\text { Fasting plasma glucose, } \\
\mathrm{mmol} / \mathrm{L}\end{array}$ & $5.85 \pm 2.30$ & $7.42 \pm 3.10$ & $<0.0001^{* *}$ \\
\hline LDL-cholesterol, mmol/L & $3.32 \pm 0.80$ & $3.38 \pm 0.77$ & 0.628 \\
\hline Triglyceride, mmol/L & $1.15(0.88-1.47)$ & $1.88(1.36-2.47)$ & $<0.0001^{* *}$ \\
\hline $\mathrm{HDL}$-cholesterol, mmol/L & $1.71 \pm 0.33$ & $1.48 \pm 0.38$ & $<0.0001^{* *}$ \\
\hline Adiponectin, $\mu \mathrm{g} / \mathrm{mL}$ & $8.95(5.53-12.2)$ & $7.80(4.80-10.9)$ & $0.050^{*}$ \\
\hline AT-LDL, $\mu \mathrm{g} / \mathrm{mL}$ & $3.27 \pm 1.02$ & $3.00 \pm 0.98$ & 0.071 \\
\hline
\end{tabular}

MetS: metabolic syndrome, LDL: low-density lipoprotein, HDL: high-density lipoprotein, $\alpha 1$-AT-LDL: $\alpha 1$-antitrypsin-low-density lipoprotein. Data are expressed as the mean \pm standard deviation, the median (interquartile range) or the percentage in each subject group. Significance level (subjects without MetS vs. those with MetS; unpaired t-test [triglyceride and adiponectin were log-transformed] or $\chi^{2}$ test): * $P \leq 0.05,{ }^{* *} P \leq 0.01$. index $(\mathrm{BMI}) \geq 25.0 \mathrm{~kg} / \mathrm{m}^{2}$ as a surrogate for Japanese subjects [22], 2) elevated blood pressure (BP) identified by systolic $\mathrm{BP}(\mathrm{SBP}) \geq 130 \mathrm{mmHg}$ and/or diastolic $\mathrm{BP}$ (DBP) $\geq 85 \mathrm{mmHg}, 3$ ) hypertriglyceridemia identified by serum triglyceride $(\mathrm{TG}) \geq 1.69 \mathrm{mmol} / \mathrm{L}, 4)$ decreased HDL-cholesterol identified by serum HDL-cholesterol $<1.29 \mathrm{mmol} / \mathrm{L}$, and 5) elevated glucose status identified by a fasting plasma glucose $(\mathrm{FPG}) \geq 6.1 \mathrm{mmol} / \mathrm{L}$. The study was approved by the Jichi Medical University ethics committee, and all subjects gave their informed consent.

Current smoking was defined as the presence of current smoking habits via a self-report and professional interview. In addition to the BMI, the SBP and DBP levels were determined in the seated subject's right-arm with a mercury sphygmomanometer after 5 minutes of rest. During an overnight fast, the serum TG and FPG levels were measured using enzymatic methods, and the serum LDL-cholesterol and HDL-cholesterol levels were measured using homogeneous methods. The serum adiponectin levels were measured with an enzyme-linked immunosorbent assay (Otsuka Pharmaceutical Co. Ltd., Tokyo, Japan). Serum AT-LDL levels were determined according to an enzyme-linked immunosorbent assay method, as described previously $[18,19]$. Briefly, fresh serum samples $(50 \mathrm{~L} /$ well $)$ were incubated overnight at $4^{\circ} \mathrm{C}$ with the anti-human AT-specific antibody (DAKO Denmark A/S, Glostrup, Denmark: AT-LDL, clone No.27) coated onto a microtiter plate. After washing, a biotinylated Fab' anti-human apo-B antibody was added as the capture antibody (100 L/well), and reacted for 2 hours at room temperature. The activity was measured in terms of the difference in optical absorbance between 450 and $620 \mathrm{~nm}$ after adding a peroxidase substrate, when the reaction was terminated by adding phosphoric acid. The intraassay coefficients of variation at low and high concentrations of AT-LDL were $1.8 \%$ and $1.6 \%$, respectively. The interassay coefficients of variation at low and high concentrations of AT-LDL were $5.9 \%$ and $5.4 \%$, respectively. All samples were assayed in duplicate and in random order.

The data were expressed as the means \pm standard deviation (SD) or the median plus interquartile range. The data between the subject groups were compared using an unpaired t-test. A simple and multivariateadjusted linear regression model was utilized to observe the correlation between AT-LDL and other atherosclerotic variables. All of the measured variables, except for DBP (because of its close collinearity to SBP: correlation coefficient $>0.6$ ), were entered into the multivariate-adjusted analysis model. The levels of TG and adiponectin were log-transformed for all of the analyses because of their skewed distributions. A P value $\leq 0.05$ was considered to be statistically significant. 


\section{Results}

With regard to the clinical characteristics of the subject groups with and without MetS (Table 1), subjects with MetS had significantly higher BMI, SBP, DBP, FPG and TG levels than those without MetS. The subjects with MetS showed significantly lower levels of HDLcholesterol and adiponectin than those without MetS. There were no significant differences in AT-LDL levels between the two subject groups.

In the simple linear regression analysis (Table 2), ATLDL was significantly and positively correlated with LDL-cholesterol, HDL-cholesterol and adiponectin in the subjects without MetS. In the group with MetS, ATLDL was significantly and positively correlated with LDL-cholesterol only. In a subsequent multivariateadjusted analysis (Table 2) in the subject group without MetS, the AT-LDL was significantly, independently and positively correlated with adiponectin, as well as HDLcholesterol. In the group with MetS, AT-LDL remained significantly, independently and positively correlated with LDL-cholesterol only.

\section{Discussion}

The present study is the first demonstration that AT-LDL had a significantly positive correlation with HDL-cholesterol and adiponectin in subjects without MetS, but not in those with MetS. In this study, subjects with MetS were more predisposed to be atherosclerotic, based on their BMI, BP, glucose/lipid panels and adiponectin, compared to those without MetS, which is in agreement with previous reports [20]. In addition, the finding of a significant correlation between AT-LDL and LDL-cholesterol in subjects with MetS was similarly observed in a previous study [19].

The present study provided two new findings. The first is the atheroprotective relevance of oxLDL. Earlier studies reported a significant inverse correlation between adiponectin and oxLDL in patients with type 2 diabetes mellitus and coronary artery disease [23] and in patients with chronic heart failure [24]. The significant inverse correlation between HDL-cholesterol and oxLDL was also reported in patients with coronary artery disease [25]. Our present results showing the significant positive correlation between adiponectin or HDL-C and AT-LDL would not have been expected from these reports [23-25], although the examined populations and oxLDL markers were different between the prior work and our current study. However, since relatively low levels of oxLDL can be atheroprotective [7-15], it is important to note the possibility that AT-LDL may exert anti-atherosclerotic effects in subjects without MetS. This might be an important case showing an atheroprotective aspect of oxLDL in the clinical setting.

Based on the current study alone, we cannot completely determine whether the significant relationship between adiponectin, HDL-cholestreol and AT-LDL is a simple (non-causative) correlation or a positive pathological link. However, we have considered the possible biological mechanisms of such a relationship. Oxidized LDL, as anti-atherosclerotic agent, acts through its cytoprotection, the modulation of immunological system and the activation of reverse cholesterol transport, as was well-documented in Yu's study [13]. The cytoprotective mechanism of oxLDL involves the regulation by the electrophile response element, including heme oxygenase-1 $[9,26]$. The atheroprotective effects of the immunity to oxLDL are known to be induced, for instance, by the secretion of anti-inflammatory cytokines, including interleukin-10 [11,13]. There is a growing appreciation that heme oxygenase-1 plays a crucial anti-inflammatory role in chronic inflammatory pathologies induced by various factors (i.e., oxidative stress and cytokines) and is a mediator of interleukin-10 expression $[27,28]$. While adiponectin induction by oxLDL remains

Table 2 Correlations of AT-LDL with other atherosclerotic variables

\begin{tabular}{|c|c|c|c|c|}
\hline \multirow[b]{2}{*}{ Variable } & \multicolumn{2}{|c|}{ Non-MetS } & \multicolumn{2}{|c|}{ MetS } \\
\hline & $\gamma(\mathrm{P}$ value $)$ & $\beta$ (P value) & $\gamma(\mathrm{P}$ value $)$ & $\beta$ (P value) \\
\hline Age, years & $-0.025(0.8001)$ & $-0.127(0.229)$ & $-0.125(0.251)$ & $-0.197(0.086)$ \\
\hline Current smoking, \% & $-0.008(0.934)$ & $0.033(0.734)$ & $0.101(0.356)$ & $0.116(0.287)$ \\
\hline Body mass index, $\mathrm{kg} / \mathrm{m}^{2}$ & $-0.073(0.452)$ & $0.081(0.447)$ & $-0.161(0.138)$ & $-0.104(0.346)$ \\
\hline Systolic blood pressure, mmHg & $0.104(0.285)$ & $0.008(0.950)$ & $0.017(0.875)$ & $0.104(0.337)$ \\
\hline Diastolic blood pressure, $\mathrm{mmHg}$ & $0.107(0.269)$ & - & $-0.131(0.229)$ & - \\
\hline Fasting plasma glucose, mmol/L & $-0.017(0.863)$ & $0.081(0.413)$ & $-0.040(0.771)$ & $0.080(0.464)$ \\
\hline LDL-cholesterol, mmol/L & $0.206(0.033)^{*}$ & $0.144(0.128)$ & $0.349(0.001)^{* *}$ & $0.342(0.002)^{* *}$ \\
\hline Triglyceride, mmol/L & $-0.022(0.819)$ & $0.016(0.860)$ & $0.204(0.061)$ & $0.167(0.120)$ \\
\hline HDL-cholesterol, mmol/L & $0.303(0.001)^{* *}$ & $0.217(0.048)^{*}$ & $-0.030(0.784)$ & $-0.006(0.965)$ \\
\hline Adiponectin, $\mu \mathrm{g} / \mathrm{mL}$ & $0.330(<0.0001)^{* *}$ & $0.297(0.010)^{* *}$ & $-0.041(0.706)$ & $-0.045(0.693)$ \\
\hline
\end{tabular}

AT-LDL: $\alpha 1$-antitrypsin-low-density lipoprotein, MetS: metabolic syndrome, LDL: low-density lipoprotein, HDL: high-density lipoprotein. r: simple linear regression coefficient between $\alpha 1$-AT-LDL and another variable, $\beta$ : multiple linear regression coefficient in a multivariate analysis for $\alpha 1-A T-L D L$ after controlling for all the listed variables except for diastolic blood pressure. Triglyceride and adiponectin were log-transformed for analyses. Significance level: * $\mathrm{P} \leq 0.05$, ${ }^{*} \mathrm{P} \leq 0.01$. 
to be established, the key molecules (such as heme oxygenase-1) can show a positive association with adiponectin [29]. Thus, the adiponectin/interleukin-10/heme oxygenase-1 pathway may, at least in part, explain the positive relationship between adiponectin and oxLDL. Furthermore, a report demonstrating that low levels of oxLDL increased cholesterol efflux in adipocytes has suggested that oxLDL has an atheroprotective role by enhancing the reverse cholesterol transport, thereby increasing HDL-cholesterol $[13,14]$. This may partly account for the positive relationship between HDLcholesterol and oxLDL.

The second major finding of our present study is the differences in associations of oxLDL with anti-atherosclerotic variables in subjects with and without MetS. The present results showing a diminished correlation between adiponectin or HDL-cholesterol and AT-LDL in subjects with MetS are interesting, and suggest that the metabolic dysregulation and homeostatic shifts specifically found in MetS subjects (i.e., lower adiponectin or HDL-cholesterol concentrations [20]) may eliminate the significant link between them found in those without MetS. Whether the pathophysiology of MetS could specifically affect the correlation pattern of atherosclerotic variables to AT-LDL remains to be explored.

The present study had a few limitations. The crosssectional design did not allow for a strict cause-andeffect conclusion to be drawn. The study was conducted in female subjects, and we did not obtain any data on males. There are also ethnic differences in some influences of atherosclerotic variables, including adiponectin and cholesterol, on atherosclerotic states [30]. Therefore, more studies with various populations and prospective designs are called for when carrying out future studies.

\section{Conclusions}

In summary, the present study showed that AT-LDL was significantly, independently and positively correlated with adiponectin and HDL-cholesterol in female subjects without MetS, but not in those with MetS. These data suggest that AT-LDL may exert anti-atherosclerotic effects in subjects without MetS. Further research is warranted to confirm these findings and their relevance in the clinical and basic settings.

\footnotetext{
Acknowledgements

This study was supported in part by a Grant-in-Aid for the Scientific Research from the Ministry of Education, Culture, Sports, Science, and Technology of Japan (K.K) and the Charitable Trust Laboratory Medicine Research Foundation of Japan (K.K).
}

\section{Authors' contributions}

All authors contributed to the intellectual development of this work, and approved the final manuscript. KK, TY and TN analyzed the data. KK searched the literature and wrote the draft paper. TY and TY provided critical corrections to the manuscript.

\section{Competing interests}

The authors declare that they have no competing interests.

Received: 17 November 2010 Accepted: 30 December 2010

Published: 30 December 2010

\section{References}

1. Lopez AD, Mathers CD, Ezzati M, Jamison DT, Murray CJ: Global and regional burden of disease and risk factors, 2001: systematic analysis of population health data. Lancet 2006, 367:1747-1757.

2. Witztum $J$, Steinberg D: Role of oxidized low density lipoprotein in atherogenesis. J Clin Invest 1991, 88:1785-1792.

3. Sawamura T, Kume N, Aoyama T, Moriwaki H, Hoshikawa H, Aiba $Y$, Tanaka T, Miwa S, Katsura Y, Kita T, Masaki T: An endothelial receptor for oxidized low-density lipoprotein. Nature 1997, 386:73-77.

4. Fraley AE, Tsimikas S: Clinical applications of circulating oxidized lowdensity lipoprotein biomarkers in cardiovascular disease. Curr Opin Lipidol 2006, 17:502-509.

5. Itabe $\mathrm{H}$, Ueda M: Measurement of plasma oxidized low-density lipoprotein and its clinical implications. J Atheroscler Thromb 2007, 14:1-11.

6. Kotani K, Satoh N, Yamada T, Gugliucci A: The potential of serum amyloid A-LDL as a novel biomarker for cardiovascular disease risk. Clin Lipidol 2010, 5:489-495.

7. Freigang S, Hörkkö S, Miller E, Witztum JL, Palinski W: Immunization of LDL receptor-deficient mice with homologous malondialdehydemodified and native LDL reduces progression of atherosclerosis by mechanisms other than induction of high titers of antibodies to oxidative neoepitopes. Arterioscler Thromb Vasc Biol 1998, 18:1972-1982.

8. Moellering DR, Levonen AL, Go YM, Patel RP, Dickinson DA, Forman HJ, Darley-Usmar VM: Induction of glutathione synthesis by oxidized lowdensity lipoprotein and 1-palmitoyl-2-arachidonyl phosphatidylcholine: protection against quinone-mediated oxidative stress. Biochem J 2002, 362:51-59.

9. Bea F, Hudson FN, Chait A, Kavanagh TJ, Rosenfeld ME: Induction of glutathione synthesis in macrophages by oxidized low-density lipoproteins is mediated by consensus antioxidant response elements. Circ Res 2003, 92:386-393.

10. Robbesyn F, Salvayre R, Negre-Salvayre A: Dual role of oxidized LDL on the NF-kappaB signaling pathway. Free Radic Res 2004, 38:541-551.

11. Shah PK, Chyu KY, Fredrikson GN, Nilsson J: Immunomodulation of atherosclerosis with a vaccine. Nat Clin Pract Cardiovasc Med 2005 2:639-646

12. van Puijvelde $G H$, Hauer $A D$, de Vos $P$, van den Heuvel $R$, van Herwijnen MJ, van der Zee R, van Eden W, van Berkel TJ, Kuiper J: Induction of oral tolerance to oxidized low-density lipoprotein ameliorates atherosclerosis. Circulation 2006, 114:1968-1976.

13. Yu BL, Zhao SP, Huang XS: Oxidized low-density lipoprotein: a doubleedged sword on atherosclerosis. Med Hypotheses 2007, 69:553-556.

14. Zhao SP, Yu BL, Xie XZ, Dong SZ, Dong J: Dual effects of oxidized lowdensity lipoprotein on LXR-ABCA1-apoA-I pathway in 3T3-L1 cells. Int J Cardiol 2008, 128:42-47.

15. Nilsson J, Fredrikson GN, Björkbacka H, Chyu KY, Shah PK: Vaccines modulating lipoprotein autoimmunity as a possible future therapy for cardiovascular disease. J Intern Med 2009, 266:221-231.

16. Knoell DL, Ralston DR, Coulter KR, Wewers MD: Alpha 1-antitrypsin and protease complexation is induced by lipopolysaccharide, interleukin1 beta, and tumor necrosis factor-alpha in monocytes. Am J Respir Crit Care Med 1998, 157:246-255.

17. Moraga F, Janciauskiene S: Activation of primary human monocytes by the oxidized form of alpha1-antitrypsin. J Biol Chem 2000, 275:7693-7700

18. Mashiba S, Wada Y, Takeya M, Sugiyama A, Hamakubo T, Nakamura A Noguchi N, Niki E, Izumi A, Kobayashi M, Uchida K, Kodama T: In vivo complex formation of oxidized alpha(1)-antitrypsin and LDL. Arterioscler Thromb Vasc Biol 2001, 21:1801-1808.

19. Kotani K, Satoh N, Kato Y, Araki R, Koyama K, Okajima T, Tanabe M, Oishi M, Yamakage H, Yamada K, Hattori M, Shimatsu A: A novel oxidized lowdensity lipoprotein marker, serum amyloid A-LDL, is associated with obesity and the metabolic syndrome. Atherosclerosis 2009, 204:526-531.

20. Nishida M, Funahashi T, Shimomura I: Pathophysiological significance of adiponectin. Med Mol Morphol 2007, 40:55-67. 
21. Expert Panel on detection, Evaluation, and Treatment of High Blood Cholesterol in Adults: Executive summary of the third report of the National Cholesterol Education Program (NCEP) Expert panel on detection, evaluation, and treatment of high blood cholesterol in adults (Adult Treatment Panel III). JAMA 2001, 285:2486-2497.

22. Examination Committee of Criteria for 'Obesity Disease' in Japan; Japan Society for the Study of Obesity. Circ J 2002, 66:987-992.

23. Lautamäki R, Rönnemaa T, Huupponen R, Lehtimäki T, lozzo P, Airaksinen KE, Knuuti J, Nuutila P: Low serum adiponectin is associated with high circulating oxidized low-density lipoprotein in patients with type 2 diabetes mellitus and coronary artery disease. Metabolism 2007, 56:881-886.

24. Tanaka T, Tsutamoto T, Nishiyama K, Sakai H, Fujii M, Yamamoto T, Horie M: Impact of oxidative stress on plasma adiponectin in patients with chronic heart failure. Circ J 2008, 72:563-568.

25. Miyazaki T, Shimada K, Sato O, Kotani K, Kume A, Sumiyoshi K, Sato Y, Ohmura H, Watanabe Y, Mokuno H, Daida H: Circulating malondialdehyde-modified LDL and atherogenic lipoprotein profiles measured by nuclear magnetic resonance spectroscopy in patients with coronary artery disease. Atherosclerosis 2005, 179:139-145.

26. Hoekstra KA, Godin DV, Cheng KM: Protective role of heme oxygenase in the blood vessel wall during atherogenesis. Biochem Cell Biol 2004, 82:351-359.

27. Otterbein LE, Soares MP, Yamashita K, Bach FH: Heme oxygenase-1: unleashing the protective properties of heme. Trends Immunol 2003, 24:449-455.

28. O'Shea JJ, Murray PJ: Cytokine signaling modules in inflammatory responses. Immunity 2008, 28:477-487.

29. L'Abbate A, Neglia D, Vecoli C, Novelli M, Ottaviano V, Baldi S, Barsacchi R, Paolicchi A, Masiello P, Drummond GS, McClung JA, Abraham NG: Beneficial effect of heme oxygenase-1 expression on myocardial ischemia-reperfusion involves an increase in adiponectin in mildly diabetic rats. Am J Physiol Heart Circ Physiol 2007, 293:H3532-3541.

30. Forouhi NG, Sattar N: CVD risk factors and ethnicity - a homogeneous relationship? Atheroscler Suppl 2006, 7:11-19.

doi:10.1186/1476-511X-9-147

Cite this article as: Kotani et al.: The association between adiponectin, HDL-cholesterol and $\alpha 1$-antitrypsin-LDL in female subjects without metabolic syndrome. Lipids in Health and Disease 2010 9:147.

\section{Submit your next manuscript to BioMed Central and take full advantage of:}

- Convenient online submission

- Thorough peer review

- No space constraints or color figure charges

- Immediate publication on acceptance

- Inclusion in PubMed, CAS, Scopus and Google Scholar

- Research which is freely available for redistribution

Submit your manuscript at www.biomedcentral.com/submit
Biomed Central 